\title{
Economics
}

The Open-Access, Open-Assessment E-Journal

Vol. 12, 2018-59 | September 18, 2018 | http://dx.doi.org/10.5018/economics-ejournal.ja.2018-59

\section{Macroeconomic dynamics and the IS puzzle}

\author{
Raymond J. Hawkins and Chau N. Nguyen
}

\begin{abstract}
The authors solve the IS puzzle for the G7 countries. They find that five of the G7 countries have the expected significant negative relationship between the output gap and the realrate gap; the time series of the remaining two show material deviation from expected IScurve behavior. The authors show that the observed time dependence of the interaction between the output and real-rate gaps can be represented in a parsimonious and practical manner using the theory of anelasticity that unifies partial-adjustment specifications of the IS curve.
\end{abstract}

JEL C22 E3 E32 E52 E61

Keywords IS curve; Euler equation; inflation; anelasticity; monetary policy

\section{Authors}

Raymond J. Hawkins, Department of Economics, University of California, Berkeley, USA and College of Optical Sciences, University of Arizona, Tucson, USA, hawkins@econ.berkeley.edu Chau N. Nguyen, Department of Economics, University of California, Berkeley, CA, USA

Citation Raymond J. Hawkins and Chau N. Nguyen (2018). Macroeconomic dynamics and the IS puzzle. Economics: The Open-Access, Open-Assessment E-Journal, 12 (2018-59): 1-13. http://dx.doi.org/10.5018/economics-ejournal.ja.2018-59 


\section{Introduction}

New Keynesian macroeconomic dynamics is based on three major elements: a central bank that seeks to keep economic output as close to the economy's highest level of sustainable output and to keep inflation as close to a target level as possible, a Phillips curve that expresses how a deviation of output from potential drives changes in inflation, and an IS curve that expresses economic output as inversely related to the level of the real interest rate. ${ }^{1}$ The latter of these - the relationship between output and the real interest rate - is the basis for the use of interest rates as the primary tool of monetary policy by central banks in advanced economies. Despite the centrality of the IS curve to monetary policy since the late 1970s the small empirical literature dedicated to establishing that an increase in the real rate does in fact have a negative impact on output has come to be characterized as the "IS puzzle": a statistically significant IS-curve is not found in some studies of the United States and is not seen in any of the other G7 countries. ${ }^{2}$ The goal of this paper is to solve the IS puzzle.

\section{The IS Puzzle}

The IS puzzle began with empirical results that supported the existence (i.e., statistical significance) of the IS curve in the U.S. (Rudebusch and Svensson, 1999; Peersman and Smets, 1999) and the EU5 (Peersman and Smets, 1999). The IS puzzle emerged (and was coined) in subsequent work by Nelson $(2001,2002 a, b)$ on U.S. and U.K. data which showed that the existence of the IS curve depended on the time frame of the data used in the analysis. A subsequent empirical reaffirmation of the IS curve in the U.S. by Fuhrer and Rudebusch (2004) was followed, shortly thereafter, by another finding of the IS puzzle, this time by Goodhart and Hofmann $(2005 \mathrm{a}, \mathrm{b})$ in their examination of the G7. The IS puzzle was also found by Angeloni and Ehrmann (2007) in the euro area, by Hafer et al. (2007) in the U.S., by Hafer and Jones (2008) in the U.S. and other countries, and by Stracca (2017) in their examination of the IS curve, its puzzle, and a similar phenomenon in the analysis of the classic consumption Euler equation.

Our approach to solving the IS puzzle is motivated by the work of Rudebusch and Svensson $(1999,2002)$ and of Goodhart and Hofmann $(2005 a, b)$ that illustrates the IS puzzle in the United States. These studies employed the specification:

$$
y_{t+1}=\beta_{y_{1}} y_{t}+\beta_{y_{2}} y_{t-1}+\beta_{r} \frac{1}{4} \sum_{j=0}^{3}\left(i_{t-j}-\pi_{t-j}\right)
$$

\footnotetext{
1 See, for example, Goodfriend and King (1997), Clarida et al. (1999), and Woodford (2003). The IS curve is also known as the intertemporal Euler equation or the output Euler equation.

2 These results are established in Rudebusch and Svensson (1999, 2002), Peersman and Smets (1999), Nelson (2001, 2002a,b), Fuhrer and Rudebusch (2004), Goodhart and Hofmann (2005a,b), Angeloni and Ehrmann (2007), Hafer et al. (2007), Hafer and Jones (2008), and Stracca (2017).
} 
Table 1: The data sources and methodologies used to generate the IS puzzle in the United States.

\begin{tabular}{cccc}
\hline Source & Sample & Potential GDP & Inflation \\
\hline Rudebusch \& Svensson & $1961-1996$ & CBO & CWPI \\
Goodhart \& Hofmann & $1982-1998$ & HP filter & CPI \\
\hline
\end{tabular}

Note: The input sources used by Rudebusch and Svensson $(1999,2002)$ are (i) the congressional budget office (CBO) estimates of potential GDP and (ii) the GDP chain-weighted price index (CWPI) for inflation. Those used by Goodhart and Hofmann (2005a,b) are (i) a Hodrick-Prescott filter calculation of potential GDP and (ii) the consumer price index (CPI) for inflation.

where $y_{t}$ denotes the output gap at time $t$ and where $i_{t}$ and $\pi_{t}$ are the nominal interest rate and the inflation rate, respectively. ${ }^{3}$ Using the data shown in Table 1 Rudebusch and Svensson (1999) and Goodhart and Hofmann (2005a,b) obtained the coefficients for Eq (1) shown under the column heading of "Puzzle" in Table 2. Rudebusch and Svensson (1999) obtained a statistically significant value for $\beta_{r}$ while Goodhart and Hofmann (2005a,b) did not; this is the IS puzzle in the United States. While the work of Rudebusch and Svensson (1999) considered only the United States, Goodhart and Hofmann (2005a,b) also found the IS puzzle to hold across the G7; in their work no G7 country was found to have a statistically significant value for $\beta_{r}$.

The heterogeneity of the entries in Table 1 - the time range, input for the GDP-gap calculation, and input for the real-rate calculation all differ - suggests that in these differences may lie the source of the IS puzzle. We localized the sources of the IS puzzle by first reproducing the results of Rudebusch and Svensson (1999) and of Goodhart and Hofmann (2005a,b) and then, having established the reproducibility of these results, varying the input data as illustrated in Table 2. As mentioned above, the IS puzzle of the United States is shown in the column labeled "Puzzle". In the upper panel of the column labeled "Puzzle" the IS-curve coefficients (the $\beta$ s) and associated $t$-statistics of Rudebusch and Svensson (1999) are shown. All betas are statistically significant and the sign of $\beta_{r}=-0.10$ is negative; all as expected for the IS curve. By contrast Goodhart and Hofmann $(2005 \mathrm{a}, \mathrm{b})$ find a statistically insignificant $\beta_{r}=-0.021$ shown in the lower panel; not as expected for the IS curve.

Our reproduction of the Rudebusch and Svensson (1999) result is shown in the upper panel of Table 2 in the column labeled CWPI. Our coefficient values are consistent with those of Rudebusch and Svensson (1999) and we therefore conclude that their results for the IS curve can be reproduced. Similarly, our reproduction of the Goodhart and Hofmann $(2005 \mathrm{a}, \mathrm{b})$ results are shown in the lower panel of Table 2 in the column labeled CPI. Our results are consistent with those of Goodhart and Hofmann (2005a,b) both for the statistically-significant coefficients and for the identity of the statistically-insignificant coefficient. We thus conclude that the results of Goodhart and Hofmann (2005a,b) can also be reproduced and this, together with our reproduction of Rudebusch and Svensson (1999), is our reproduction of the IS puzzle.

\footnotetext{
3 The output gap is the percent deviation of actual real economic output $q_{t}$ from potential real output $q_{t}^{*}$ given by $y_{t}=100\left(q_{t}-q_{t}^{*}\right) / q_{t}^{*}$ and the annual inflation rate $\pi_{t}$ is calculated from a quarterly inflation index $p_{t}$ using $\pi_{t}=400\left(\ln p_{t}-\ln p_{t-1}\right)$.
} 
Table 2: Coefficients and associated $t$-statistics (in parenthesis) for the IS curve in the United States given by Eq. (1). Asterisks indicate significance at the 1 percent $(* * *)$ and 5 percent $(* *)$ levels; $(\dagger)$ indicates reported significance at least at the 10 percent level by Goodhart and Hofmann (2005a,b). The data for this analysis was obtained from the Federal Reserve Bank of St. Louis Economic Data Data (FRED) website.

\begin{tabular}{|c|c|c|c|c|}
\hline & Puzzle & CWPI & CPI & PCE \\
\hline \multicolumn{5}{|c|}{ 1961-1996: } \\
\hline$\beta_{y_{1}}$ & $\begin{array}{l}1.16 \\
(14.5)\end{array}$ & $\underset{(14.70)}{1.185^{* * *}}$ & $\begin{array}{c}1.224^{* * * *} \\
(15.20)\end{array}$ & $\frac{1.200^{* * *}}{(14.85)}$ \\
\hline$\beta_{y_{2}}$ & $\begin{array}{l}-0.25 \\
(-3.2)\end{array}$ & $\begin{array}{c}-0.278^{* * *} \\
(-3.51)\end{array}$ & $\begin{array}{c}-0.304^{* * *} \\
(-3.80)\end{array}$ & $\begin{array}{c}-0.288^{* * *} \\
(-3.62)\end{array}$ \\
\hline$\beta_{r}$ & $\begin{array}{l}-0.10 \\
(-3.3)\end{array}$ & $\begin{array}{c}-0.073^{* *} \\
(-2.40)\end{array}$ & $\begin{array}{c}-0.016 \\
(-0.53)\end{array}$ & $\begin{array}{c}-0.057 \\
(-1.81)\end{array}$ \\
\hline \multicolumn{5}{|c|}{ 1982-1998: } \\
\hline$\beta_{y_{1}}$ & $\begin{array}{l}1.308^{\dagger} \\
(12.12)\end{array}$ & $\begin{array}{c}1.362^{* * * *} \\
(14.27)\end{array}$ & $\begin{array}{c}1.367^{* * * *} \\
(14.49)\end{array}$ & $\begin{array}{c}1.361^{* * *} \\
(14.13)\end{array}$ \\
\hline$\beta_{y_{2}}$ & $\begin{array}{c}-0.457^{\dagger} \\
(-4.37)\end{array}$ & $\begin{array}{c}-0.441^{* * *} \\
(-4.62)\end{array}$ & $\begin{array}{c}-0.440^{* * *} \\
(-4.66)\end{array}$ & $\begin{array}{c}-0.440^{* * *} \\
(-4.60)\end{array}$ \\
\hline$\beta_{r}$ & $\begin{array}{c}-0.021 \\
(-0.66)\end{array}$ & $\underset{(0.03)}{0.001}$ & $\begin{array}{c}0.019 \\
(0.66)\end{array}$ & $\begin{array}{c}0.000 \\
(0.0)\end{array}$ \\
\hline
\end{tabular}

The origins of the IS puzzle are revealed in the remaining entries of Table $2 .{ }^{4}$ We begin by examining the impact of changing the inflation measure on the coefficients. As mentioned above, Rudebusch and Svensson (1999) used the CWPI measure while Goodhart and Hofmann (2005a,b) used the CPI. The impact of the CPI measure on the Rudebusch and Svensson (1999) result can be seen by comparing the coefficients in the columns labeled CWPI and CPI in the upper panel of Table 2. Moving from CWPI to CPI eliminates the statistical significance of the real rate coefficient. For completeness we also show the result for the personal-consumption expenditure (PCE) deflator; use of this inflation measure also creates an IS puzzle. Variation of the inflation measure for the time range of Goodhart and Hofmann (2005a,b) shown in the columns labeled CWPI and PCE in the lower panel of Table 2 reveals that the lack of statistical significance for this time range is indeed robust; changing the inflation measure does not restore statistical significance to $\beta_{r}$. Thus we conclude that one source of the IS puzzle is the choice of inflation measure.

Next, comparing the coefficients in the upper and lower panels of the column labeled CWPI we find a second source of the IS puzzle; changing the time range of the input data can eliminate the statistical significance of the real-rate coefficient. Examination of the CPI and PCE columns demonstrates that this change in time range does not restore the statistical significance of the real rate in either case. Thus, we conclude that a second source of the IS puzzle is the choice of time range of the input data.

These origins of the IS puzzle - changes in the inflation measure and changes in the time range of the input data - can be seen in Figure 1 where the data used to generate the coefficients in Table 2 are shown. In panel (a) we see the output gap and the Fed Funds rate as a function of time with the grey bars indicating recessions. The three inflation measures discussed above are shown as a

\footnotetext{
4 The results in the upper panel do not change materially when the HP filter with $\lambda=1600$ is used to calculate potential output. Thus, the difference introduced by using the CBO estimate of potential GDP is not a source of the IS puzzle.
} 
Figure 1: The time series from which the IS-curve coefficients in Table 2 were calculated. The data for these figures was obtained from the Federal Reserve Bank of St. Louis Economic Data Data (FRED) website.
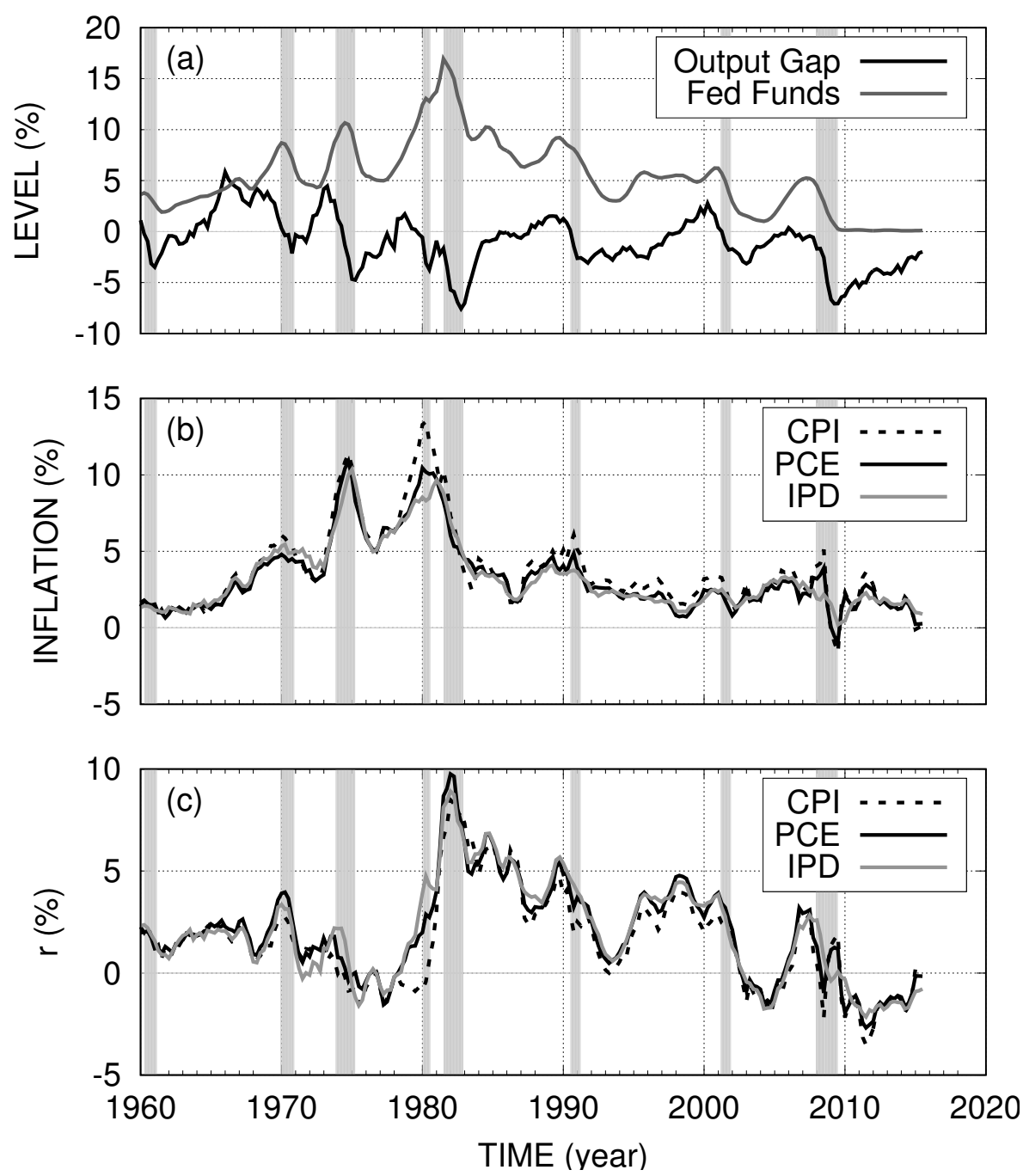

function of time in panel (b). Finally, in panel (c) we see the real rate that follows from the Fed Funds rate in panel (a) and the inflation measures in panel (b).

The reason the time range matters is likely associated with the dramatic movement in both the output gap and the real interest rate seen before 1982. To begin the analysis in 1982 is to exclude the period during which each of these variables experienced their greatest dynamic range and to focus the analysis on a period during which movement in the real rate is somewhat less correlated with the output gap. Indeed, it appears that the late 1970s and early 1980s are a sort of natural experiment regarding the IS curve designed to highlight the rate dependence of output.

Similarly, the choice of inflation matters because the time series of the CPI inflation measure differs significantly from that of the PCE and IPD inflation measures during some time intervals. Of particular importance to our study is the comparatively dramatic rise and fall of CPI inflation in 
and around 1980 shown in panel (b) of Figure 1, resulting in a materially different real rate during this time as shown in the lower panel of this figure.

This sensitivity to inflation measure, however, brings into focus the implicit manner by which the natural-rate component ${ }^{5}$ of the real-rate gap in Eq. (1) has been calculated: either as the mean rate of a demeaned time series or as a non-zero constant term in the regression. Furthermore, Eq. (1) expresses the rather strong assumption that, in contrast to the output gap, all lags of the real rate have the same coefficient. This, together with the somewhat ad hoc origin of Eq. (1) suggest a reexamination of the specification the IS curve and it is to this that we now turn.

\section{Time-Dependence of the IS Curve}

In equilibrium the IS curve is given by

$$
y=J r
$$

where $y$ is the output gap, $r$ is the real interest-rate gap (the rate gap), and $J$ is a constant that should have a negative sign. Implicit in this version of the IS curve is (i) a unique equilibrium output gap for each level of the rate gap, (ii) instantaneous achievement of the equilibrium response, and (iii) linearity of the response. The validity of these assumptions can be assessed by comparing empirical time series for the rate gap and the output gap. If valid, the temporal variation of these time series should, modulo small fluctuations, be the same.

The output and rate ${ }^{6}$ gaps for the United States are shown in Figure 2 where, contrary to the instantaneous proportionality implicit in Eq. (2), we see the dynamic monetary-policy interplay between the rate gap and the output gap, with the rate gap rising in response to an increase in the output gap and falling in response to a decline in the output gap. ${ }^{7}$ The lead-lag nature of the output-rate dynamics clearly illustrated in Figure 2 indicates that the assumption of instantaneous response of the rate gap to a change in the output gap is not supported empirically. Relaxing this assumption to allow for time-dependence in the response while maintaining linearity and the long-run equilibrium described by Eq. (2) is the basis of anelasticity and the notion of a standard anelastic economy in which the IS curve becomes ${ }^{8}$

$$
\tau_{r} \frac{d y}{d t}+y=\tau_{r} J_{U} \frac{d r}{d t}+J_{R} r
$$

\footnotetext{
5 The natural rate of interest is "the real short-term interest rate consistent with output equaling its natural rate and constant inflation." See, for example, Holston et al. (2017).

6 The rate gap for the PCE inflation measure is shown in Figure 2. The rate gaps for the other inflation measures are essentially identical to that of PCE and, in the interest of clarity, not shown.

7 To calculate the natural-rate component of the rate gap we employed the Hodrick-Prescott filter. This approach is consistent with current econometric practice for evaluating long-wavelength components of time series, provides methodological coherence across our long-wavelength calculations since we are using it to calculate the potential output in the output gap, introduces a relatively small computational deviation from the detrending approaches used by Rudebusch and Svensson (1999) and Goodhart and Hofmann (2005a,b), and is consistent with our goal of identifying the source of the IS puzzle within a formal framework as close to that of Eq. (1) as possible. Other more formally and computationally complex approaches to determining the natural rate (e.g., Laubach and Williams (2003), Garnier and Wilhelmsen (2009), Holston et al. (2017) and references therein) hold promise for future work on this issue.

8 See Hawkins (2015) and references therein.
} 
Figure 2: The output and rate gaps for the United States. The data for this figure was obtained from the Federal Reserve Bank of St. Louis Economic Data (FRED) website.

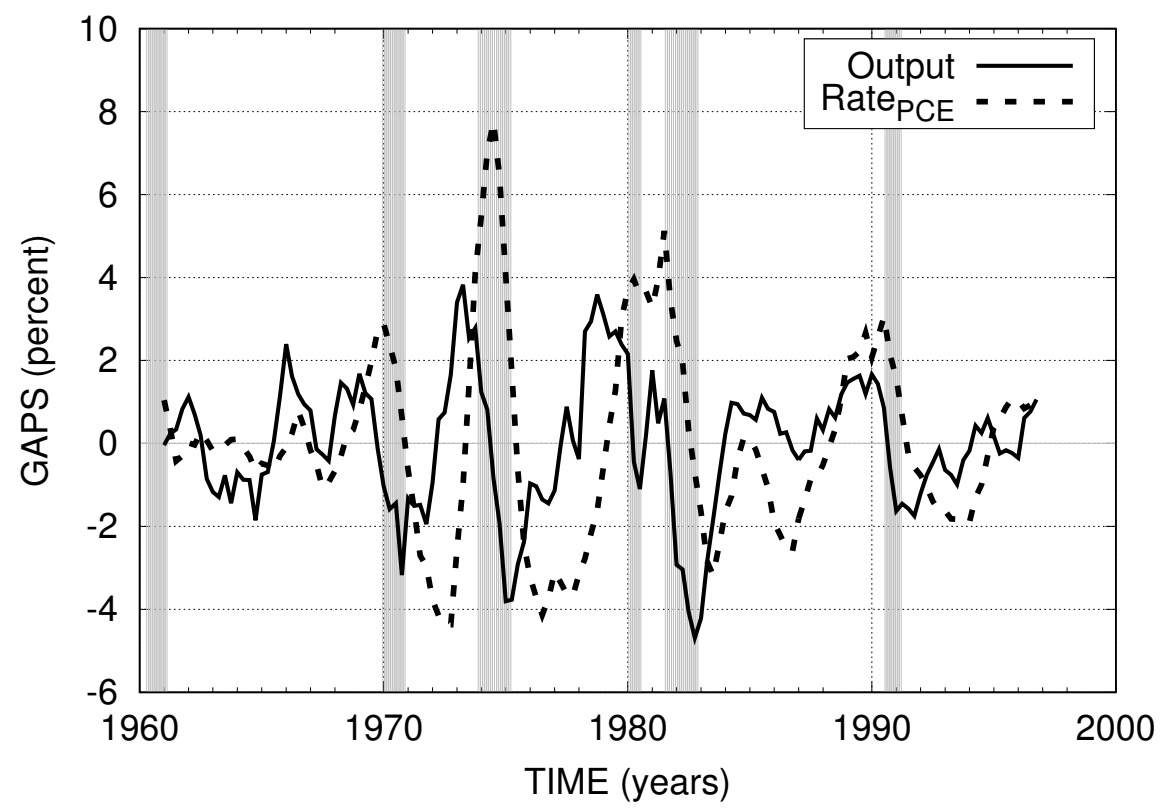

where $\tau_{r}$ is the relaxation time at constant rate gap and the proportionality constant $J$ is now represented by two terms: $J_{U}$ that represents any instantaneous response and $J_{R}$ that represents the equilibrium proportionality. The difference $J_{R}-J_{U}$ is the time-dependent component of the response. In the equilibrium limit we recover IS curve seen in Eq. (2) above as $y=J_{R} r$.

Some intuition for this dynamic form of the IS curve can be had from a consideration of a simple rate shock. If the rate gap is shocked and held at a constant level $r$ the time-dependent output gap becomes

$$
y_{t}=\left(J_{U}+\delta J\left[1-e^{-t / \tau_{r}}\right]\right) r
$$

where $\delta J \equiv\left(J_{R}-J_{U}\right)$. The output-gap response to this step change in the rate gap is illustrated in Figure 3. At $t=0$ the rate gap increases by $1 \%$ and in response to this the output gap has a very rapid response of $J_{U}=-0.50 \%$ followed by a slower relaxation to $J_{R}=-2.0 \%$.

The partial-adjustment form of the IS curve obtained by discretizing Eq. (3)

$$
y_{t+1}=y_{t}+J_{U}\left(r_{t+1}-r_{t}\right)+\frac{3}{2} \tau_{r}^{-1}\left(J_{R} r_{t}-y_{t}\right)-\frac{1}{2} \tau_{r}^{-1}\left(J_{R} r_{t-1}-y_{t-1}\right)
$$

has an output-gap lag structure similar to that of Eq. (1) but a rate-gap lag structure that differs from Eq. (1) in that each lag has a different coefficient. ${ }^{9}$ A further simplification can be had by noting that with a quarterly measurement frequency the instantaneous component of the response $J_{U}$ will not be observed; consequently we set $J_{U}=0$ and used the following form of Eq. 5 in our

9 This discretization employed here was the Adams-Bashforth 2-step method discussed by Hawkins and Arnold (2000) and references therein. 
Figure 3: An illustration of the response of the output gap to a step change in the rate gap using $J_{R}=-2, J_{U}=-0.5$, and $\tau_{r}=1.5$ years.

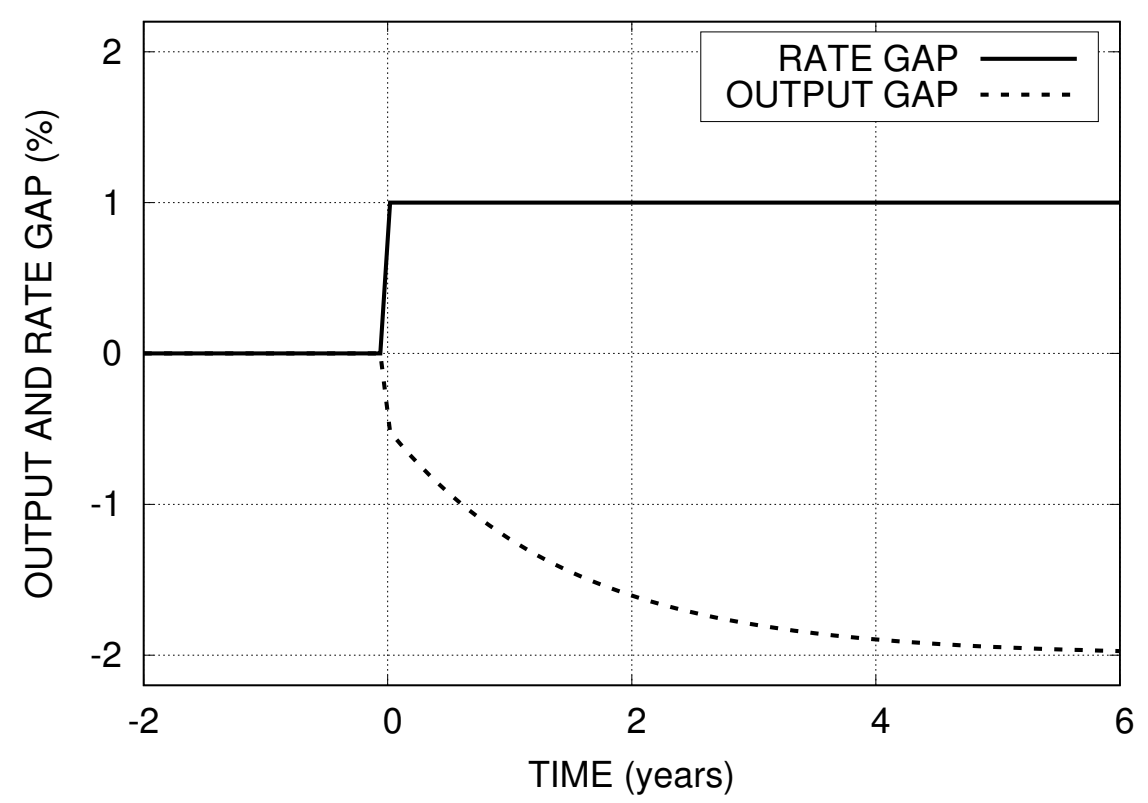

empirical analysis.

$$
y_{t+1}-y_{t}=-\frac{1}{\tau_{r}}\left(\frac{3}{2} y_{t}-\frac{1}{2} y_{t-1}\right)+\frac{J_{r}}{\tau_{r}}\left(\frac{3}{2} r_{t}-\frac{1}{2} r_{t-1}\right)
$$

The coefficients for Eq. (3), obtained by fitting Eq. (6) using ordinary least squares via the Im function in R, over the period studied by Rudebusch and Svensson $(1999,2002)$ are shown in Table 3. This analysis demonstrates that this specification is more robust to the choice of inflation measure. The proportionality constant $J_{R}$ is rather close to two in the two cases with statistically significant values for $1 / \tau_{r}$ indicating that $y \approx-2 r$ in equilibrium.

The success of our analysis in other G7 countries is contingent on the existence of the lead-lag relationship between the output gap and the rate gap found in the United States; an indication of active rate-based monetary policy. As the time series in Figure 4 illustrate, however, this appears to be the case for only a portion of the G7 countries. The output-rate relationship of the United Kingdom and Germany is similar to that of the United States with changes in output generally

Table 3: Coefficients and associated $t$-statistics (in parenthesis) for the IS curve in the United States given by Eq. (3). Asterisks indicate significance at the 1 percent $(* * *)$ and 5 percent $(* *)$ levels. The data for this analysis was obtained from the Federal Reserve Bank of St. Louis Economic Data Data (FRED) website.

\begin{tabular}{|c|c|c|c|}
\hline & CWPI & CPI & PCE \\
\hline $1 / \tau_{r}$ & $\begin{array}{c}0.086^{* *} \\
(2.49)\end{array}$ & $\begin{array}{c}0.055 \\
(1.57)\end{array}$ & $\underset{(2.05)}{0.071^{* *}}$ \\
\hline$J_{R} / \tau_{r}$ & $\begin{array}{c}-0.165^{* * *} \\
(6.41)\end{array}$ & $\begin{array}{c}-0.139^{* * *} \\
(6.25)\end{array}$ & $\begin{array}{c}-0.159^{* * *} \\
(6.36)\end{array}$ \\
\hline
\end{tabular}


Figure 4: Output and rate gaps for ex-U.S. members of the G7. The data for these figures was obtained from Global Financial Data (GFD).

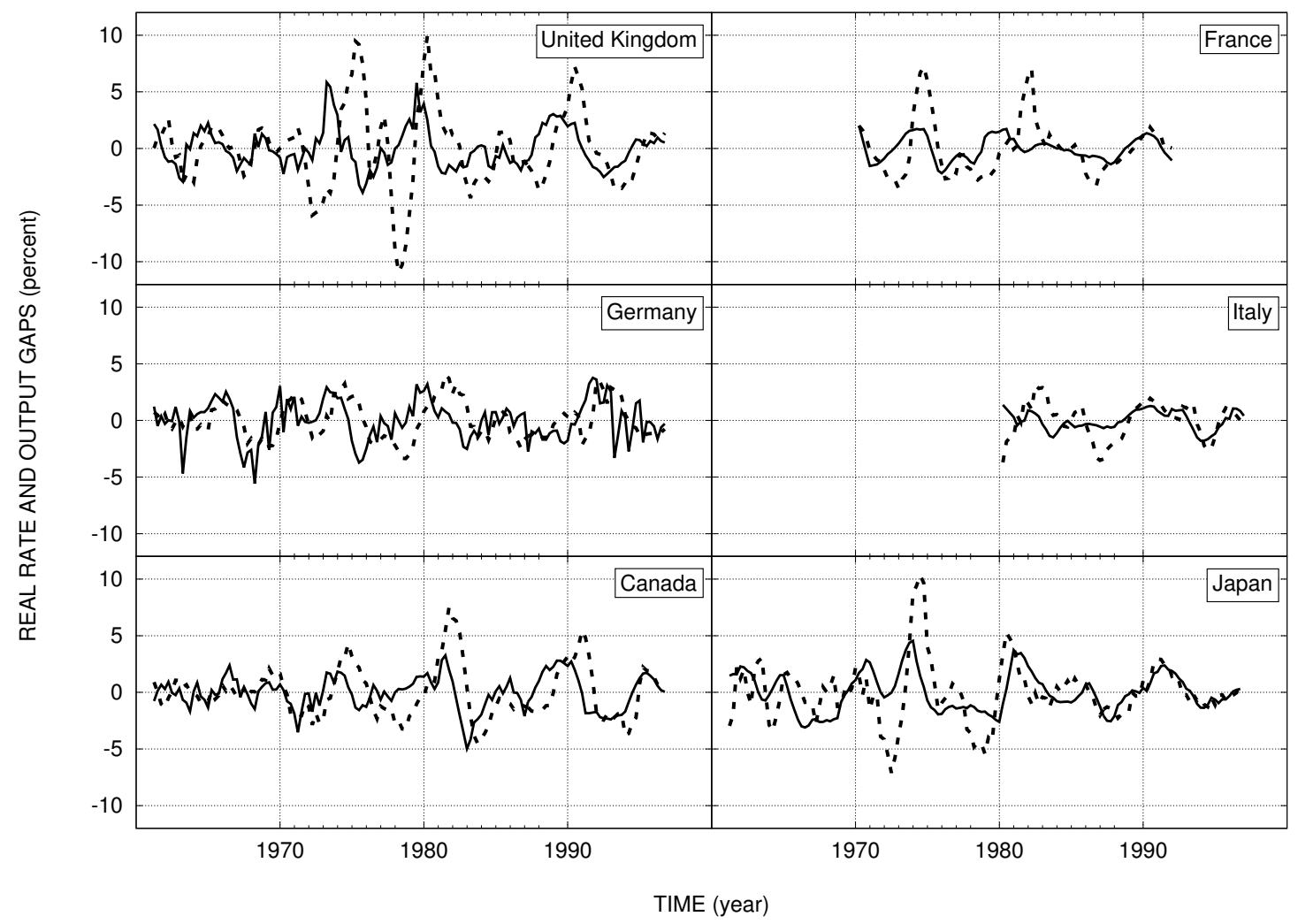

leading changes in rate, and this relationship is described well by Eq. (3) as indicated by the coefficients in Table 4. Canada, Italy, and France did not have statistically significant coefficients for $1 / \tau_{r}$. Since this suggested that the equilibrium IS curve was a more appropriate specification we ran regressions using Eq. (2) which yielded the coefficients $J$ shown in Table 4. With this equilibrium specification Canada and France are seen to have statistically significant IS curves. Italy, by contrast, does not have a statistically significant IS relationship, although this consistency with the results of Goodhart and Hofmann (2005a,b) could be due to the lack of data before 1980 . Finally, the data for Japan successfully resisted our attempts at parameterization. Inspection of the time series for Japan reveals interactions, such as the real-rate gap change leading the output gap change in 1980, that are inconsistent with the IS-curve generally and suggests a richer dynamical model is needed to describe the IS relationship in Japan. Of particular interest is that in all G7 countries except for Italy and Japan a statistically significant negative relationship between the output gap and the real-rate gap is observed, and thus it can be said that for these countries the IS puzzle is solved. 
Table 4: Coefficients and associated $t$-statistics (in parenthesis) for the IS curve given by Eqs. (2) or (3). Asterisks indicate significance at the 1 percent level (***). The data for this analysis was obtained from Global Financial Data (GFD).

\begin{tabular}{cccc}
\hline Country & $1 / \tau_{r}$ & $J_{R} / \tau_{r}$ & $J_{R}$ or $J$ \\
\hline United Kingdom & $0.152^{* * *}$ & $-0.105^{* * *}$ & -0.691 \\
Germany & $(3.82)$ & $(5.06)$ & \\
Canada & $0.268^{* * *}$ & $-0.128^{* * *}$ & -0.478 \\
France & $(5.08)$ & - & $-0.135^{* * *}$ \\
Italy & - & - & $(5.53)$ \\
& - & - & $(3.62)$ \\
& - & & -0.028 \\
\hline
\end{tabular}

Note: The values of $J_{R}$ for the United Kingdom and for Germany are the ratios of $J_{R} / \tau_{r}$ and $1 / \tau_{r}$. The retail price index (RPI) was used to calculate inflation in the United Kingdom; the consumer price index (CPI) was so used for the other G7 countries.

\section{Discussion and Summary}

As one of the three components of New Keynesian economic dynamics the IS curve is of considerable importance to academic economists, central bankers, and other policy makers. In particular, the negative dependence of the output gap on the real interest rate is fundamental to the use of interest rates as macroeconomic policy tools. Thus, the IS puzzle - the observation that the output gap is not dependent on the real rate in a statistically significant manner - is a major concern to those for whom interest rates are a key monetary policy tool.

We have found that the IS puzzle has two primary sources. First, is the choice of time range over which the relationship between the output gap and the rate gap is studied. This is perhaps the most consistent feature of the IS puzzle, having figured prominently in its discovery by Nelson $(2001,2002 a, b)$ and in all studies thereafter. If a material change in the rate gap is not present in the data, estimation of the dependence of the output-gap on the rate gap will be complicated significantly by the presence of other factors that bear on the the value of the output gap; an estimation challenge that has bested most attempts to control for other factors. Consequently, focussing on (or at least including) a period of time during which the functional relationship one is attempting to estimate is the primary (in terms of magnitude) effect seen in the data provides as close to a controlled experiment as one is likely to encounter in this area of macroeconomics. Indeed, one is reminded of Fisher's (1925) comment on his choice of time frame when studying the relationship between inflation and output which, adapted to our examination of the IC curve, reads; "[t]his period seemed the most suitable for the purpose (namely to obtain the best estimate of the true influence of [rate changes] on [output]) chiefly because, during this period the [rate] changes were so great."

The second primary source is lack of robustness of the IS curve as specified by Eq. (1). We found that the sensitivity of the IS curve with respect to inflation measure was reduced significantly by using an anelastic specification of the IS curve that relaxes the treatment of the real rate given 
by Eq. (1) to one in which the temporal evolution of the rate gap is on the same footing as that of the output gap. The anelastic specification of the IS curve has a natural extension to other variables ${ }^{10}$ and the application of this specification to the variables proposed by Nelson (2001, 2002a,b), Goodhart and Hofmann (2005a,b), and Hafer and Jones (2008) represents an interesting opportunity for future work. Another promising opportunity along this line are enhancements in the estimation of the real rate developed by Laubach and Williams (2003) and furthered by Garnier and Wilhelmsen (2009) and Holston et al. (2017).

In summary, we have shown that the IS puzzle is a result of both the chosen time-range of the data used to study the IS curve and the specification of the IS curve. With a time-range chosen to include a materially dynamic range for the real-rate gap and a specification of the IS curve that includes a time-dependent natural rate the real-rate gap the IS puzzle in the G7 countries can be solved.

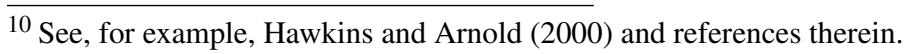




\section{References}

Angeloni, I., and Ehrmann, M. (2007). On money and output: Is money redundant? B.E. J. Macro., 7(1): 1935-1690. URL https://doi.org/10.2202/1935-1690.1509.

Clarida, R., Gali, J., and Gertler, M. (1999). The science of monetary policy: A New Keynesian perspective. J. Econ. Lit., 37(4): 1661-1707. URL http://dx.doi.org/10.1257/jel.37.4.1661.

Fisher, I. (1925). Our unstable dollar and the so-called business cycle. Journal of American Statistical Association, 20(150): 179-202. URL https://doi.org/10.1080/01621459.1925.10502140.

Fuhrer, J. C., and Rudebusch, G. D. (2004). Estimating the Euler equation for output. J. Mon. Econ., 51(6): 1133-1153. URL https://doi.org/10.1016/j.jmoneco.2003.10.004.

Garnier, J., and Wilhelmsen, B.-R. (2009). The natural rate of interest and the output gap in the euro area: A joint estimation. Empir. Econ., 36: 297-319. URL http://dx.doi.org/10.1007/ s00181-008-0196-z.

Goodfriend, M., and King, R. (1997). The new neoclassical synthesis and the role of monetary policy. NBER Macroeconomics Annual, 12: 231-296. URL http://dx.doi.org/10.1086/654336.

Goodhart, C., and Hofmann, B. (2005a). The IS curve and the transmission of monetary policy: Is there a puzzle? Appl. Econ., 37(1): 29-36. URL http://dx.doi.org/10.1080/ 0003684042000280355 .

Goodhart, C., and Hofmann, B. (2005b). The Phillips curve, the IS curve and monetary transmission: Evidence for the U.S. and the euro area. CESifo Econ. Stud., 51(4): 757-775. URL https://doi.org/10.1093/cesifo/51.4.757.

Hafer, R., Haslag, J. H., and Jones, G. (2007). On money and output: Is money redundant? J. Mon. Econ., 54(3): 945-954. URL https://doi.org/10.1016/j.jmoneco.2005.06.004.

Hafer, R. W., and Jones, G. (2008). Dynamic IS curves with and without money: An international comparison. J. Int. Money Finance, 27(4): 609-616. URL http://dx.doi.org/10.1016/j.jimonfin. 2008.02.005.

Hawkins, R. J. (2015). Okun's law and anelastic relaxation in economics. J. Econ. Interact. and Coord., 10(1): 151-161. URL http://dx.doi.org/10.1007/s11403-014-0128-2.

Hawkins, R. J., and Arnold, M. R. (2000). Relaxation processes in administered-rate pricing. Phys. Rev. E, 62(4): 4730-4736. URL https://doi.org/10.1103/PhysRevE.62.4730.

Holston, K., Laubach, T., and Williams, J. C. (2017). Measuring the natural rate of interest: International trends and determinants. Int. Econ. URL http://dx.doi.org/10.1016/j.jinteco.2017. 01.004 .

Laubach, T., and Williams, J. C. (2003). Measuring the natural rate of interest. Rev. Econ. Stat., 85(4): 1063-1070. URL http://dx.doi.org/10.1162/003465303772815934. 
Nelson, E. (2001). What does the UK's monetary policy and inflation experience tell us about the transmission mechanism? CEPR Discussion Papers 3047, Center for Economic and Policy Research. URL https://ssrn.com/abstract=290521.

Nelson, E. (2002a). Direct effects of base money on aggregate demand: theory and evidence. Monetary Econ., 49: 687-708. URL http://dx.doi.org/10.1016/S0304-3932(02)00118-6.

Nelson, E. (2002b). What does the UK's monetary policy and inflation experience tell us about the transmission mechanism? In Monetary Transmission in Diverse Economies, pages 137-155. Cambridge University Press.

Peersman, G., and Smets, F. (1999). The Taylor rule: A useful monetary policy benchmark for the euro area? Int. Finance, 2(1): 85-116. URL http://dx.doi.org/10.1111/1468-2362.00020.

Rudebusch, G., and Svensson, L. E. O. (1999). Policy rules for inflation targeting. In Monetary Policy Rules, chapter 5, pages 203-262. Chicago, IL: University of Chicago Press.

Rudebusch, G., and Svensson, L. E. O. (2002). Eurosystem monetary targeting: Lessons from U.S. data. Eur. Econ. Rev., 46(3): 417-442. URL http://dx.doi.org/10.1016/S0014-2921(01) 00163-5.

Stracca, L. (2017). The Euler equation around the world. B.E. J. Macro., 17(2): 2013-0117. URL https://doi.org/10.1515/bejm-2013-0117.

Woodford, M. (2003). Interest and prices: Foundations of a theory of monetary policy. Princeton University Press. 


\section{Economics}

Please note:

You are most sincerely encouraged to participate in the open assessment of this article. You can do so by either recommending the article or by posting your comments.

\section{Please go to:}

http://dx.doi.org/10.5018/economics-ejournal.ja.2018-59

The Editor 